\title{
Otomasi pada Sistem Flow Meter
}

\author{
Rizqi Zainur Ridho \#, Muhammad Ridha Mak'ruf, Moch Prastawa Assalim Tetra Putra \\ Departemen Electromedical Teknik Poltekkes Kemenkes, Surabaya \\ Jl. Pucang Jajar Timur No. 10, Surabaya, 60245, Indonesia \\ \#0km.indonesia@gmail.com,m.reedha@gmail.com,mpatp@yahoo.com
}

\begin{tabular}{l}
\hline \multicolumn{1}{c}{ Info Artikel } \\
\hline Penerimaan Artikel: \\
Diterima 9 Maret 2019 \\
Revisi 15 Des 2020 \\
Terbit 18 Des 2020 \\
\end{tabular}

Kata kunci:

Flow Meter

Spo2

Hipoxia

Oxygen

\begin{abstract}
Abstrak
Pemberian oxygen terapi pada pasien yang beresiko mengalami hipoxsemia atau sudah mengalami hepoxemia haruslah selalu dipantau oleh perawat pada waktu ke waktu, hal ini dilakukan untuk memastikan apakah pembukaan katup oxygen flow meter sudah sesuai dengan dosis yang mengacu pada Spo2 pasien. Tujuan dari penelitian untuk mempemudah tugas perawat melakukan pemantauan kadar Spo2 pasien dan secara otomatis mengatur pembukaan katup oxygen flow meter. Kontribusi penelitian ini adalah sistem yang dapat memantau kadar oxygen pasien dan mengatur otomatis mengatur pemberian oxygen theraphy. Agar dapat mengatur pembukaan oxygen flow meter sesuai dengan kadar SPO2 pasien peneliti membuat sistem mekanik pembukaan flow meter oxygen yang tersambung langsung dengan Spo2. Sensor fingertip yang terpasang pada jari pasien akan mendeteksi kadar Spo2 pasien. Lalu diolah pada mikrokontroler untuk mengatur pembukaan katup flow meter oxygen. Pada pembacaan kadar Spo2 89 - $91 \%$ pembukaan katup berada pada titik 2 LPM, pada pembacaa kadar Spo 2 dibawah $88 \%$ pembukaan katup berada pada titik 6 LPM dan pada pembacaan $\mathrm{Spo2}$ di atas $\mathbf{9 2 \%}$ maka katup oxygen flow meter akan menutup secara berkala. Hasil penelitian ini menunjukkan bahwa pembukan katup flow meter oxygen pada titik $92 \%-88 \%$ mempunyai error rata rata $1-2 \%$.
\end{abstract}

\begin{abstract}
Oxygen theraphy dilivery in patients who have the risk for hipoxia or alrady have hipoxia case must be monitored in time to time, the purpose of this monitoring is to make sure that the patients has already have the right dose of oxygen theraphy delivery due to the presentage of patients Spo2. the purpose of this research is to simplefy nurse's job to monitoring the Spo2 patient and automaticly control the opening of oxygen flow meter valve for oxygen theraphy delivery. The contributuion of this reaserch is to make a system that can monitor the presentage of Spo2 patients and automaticly control the opening the valve of oxygen flow meter due to the presentage of Spo2 patients. In order to control the valve of oxygen flow meter based on Spo2 patients the researcher make a mechanical system that can automaticly contorl the opening of the valve that directly conencted with Spo2 sensor. sensor fingertip that placed to patients will read the Spo2 presentage, and the presentage's will automaticly determain how much the valve is open.In $89 \%$ - 92\% Spo2 readings the valve will open at 2 LPM, in $88 \%$ below the valve wil open at 6 LPM, and if the presentage is $92 \%$ or above the valve will close gradualy. the result of this research is showed that the opening of the valve when the presentage is in $92 \%$ - $88 \%$ below have an $1 \%-2 \%$ presentage of error. the result of this research can expanded in the next research..
\end{abstract}

Penulis korespondensi:

Muhammad Ridha Mak'ruf

Departemen Electromedical Teknik

Poltekkes Kemenkes, Surabaya

Jl. Pucang Jajar Timur No. 10, Surabaya, 60245, Indonesia

Email:m.reedha@gmail.com
This work is an open access article and licensed under a Creative Commons Attribution-ShareAlike 4.0 International License(CC BY-SA 4.0).

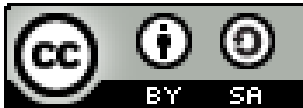

\section{Pendahuluan}

Permasalahan pada saat perawat memberikan oxygen therapy pada pasien yang membutuhkan tambahan oxygen dengan menggunakan flow meter manual adalah perawat haruslah memantau secara berkala kondisi Spo2 pasien sebagai acuan dosis pemberian oxygen[1][2], dikarenakan Oxygen therapy merupakan bagian yang penting untuk penanganan pasien pada saat dalam kondisi kritis[3], Untuk dapat memenuhi kebutuhan oxygen oragan vital tubuh pada pasien[4][5]. sehingga menghindari terjadinya kondisi dimana kadar oxygen dalam darah menurun kedalam level yang tidak aman (hypoxemia)[1][6]. Dikarenakan keadaan tersebut akan menyebabkan oragan-organ tubuh tidak akan mendapatkan oxygen yang cukup (hypoxia)[7][8][9], dalam kondisi tertentu 
pasien seringkali membutuhkan oxygen tambahan dengan konsentrasi yang tinggi[4][10][11].

Meskipun oxygen therapy dapat membantu pasien untuk proses penyembuhan maupun proses pemulihan[12], oxygen therapy mempunyai bahaya dan efek samping tertentu[1][13], siapapun yang bertanggung jawab dengan pemberian oxygen therapy harus paham akan potensi bahaya dan efek samping yang di timbulkannya[14]. Salah satu bahaya yang akan muncul ketika tidak ada pengawasan terhadap oxygentherapy adalah hypoximia dan oxygen toxicity[15]. Oxygen toxicity disebabkan oleh pemberian oxygen secara berlabihan atau tidak sesuai dengan kondisi pasien[16]. Oxygen toxicity dapat menyebabkan kerusakan pada paru-paru dan organ yang lain[1][17]. Karena alasan tersebut pemberian oxygen therapy haruslah sesuai dengan dosis yang seharusnya dengan memantau secara terus menerus tingkat SpO2[18] pasien dan melakukan penyesuaian regulator oxygen (oxygen flow meter)[19]berdasarkan tingkat SpO2. sehingga tingkat $\mathrm{SpO} 2$ pasien sesuai dengan target yang aman sesuai dengan kondisi dan keadaan pasien[5][18].Terkadangan keakurasian output pada flow meter manual tidaklah baik dikarenakan bola kecil yang di pakai sebagai acuan keluarnya aliran flow oxygen dapat tersendat dikarenakan kotor[20], dan perawat tidak mengetahui hal tersebut, sehingga membuat "sefty pasien" berkurang[19][1]. Maka dari itu peneliti bertujuan untuk melakukan pemodifikasian flow meter manual untuk menjadi flow meter otomatis, dengan menggunakan sensor tekanan sebagai parameter aliran flow dan motor stepper sebagai pembukan katup flow meter secara otomatis, sehingga tugas perawat akan lebih mudah untuk untuk memberikan oxygen tambahan pada pasien dan membuat sefty pasien bertambah.

Bedasrakan uraian penjelasan studi pustaka yang telah diuraikan ada beberapa hal yang harus diselesaikan melali sebuah penelitian lebih lanjut antara lain 1) Meneliti sistem pada flow meter manual, 2) Melakukan uji sensor yang digunakan sebagai sistem utama alat 3) merancang pemodifikasian flow meter manual untuk bisa dibuat menjadi otomatis. Oleh karena itu pada penelitian ini akan di rancang sebuah penelitian untuk mempelajari sistem flow meter oxygen manual, selanjutnya merancang sistem mekanik dan sistem elektronik dengan tujuan agar flow meter manual dapat dimodifikasi menjadi flow meter otomatis dengan parameter spo2 pasien. Penggunaan rancangan ini akan lebih efektif karena menggunakan sensor untuk mendeteksi aliran flow yang sedang di gunakan, dan menggunakan putaran gear untuk membuka katup oxygen flow meter secara otomatis.

Artikel ini terdiri dari 5 bagian, bagian I merupakan penjelasan tentang pendahuluan dan latar belakang, bagian II berisi metode dan pengembangan yang akan dilakukan, bagian III merupakan hasil hasil yang di dapatkan pada penelitian ini, bagian ke IV adalah pembahasan temuan temuan, dan bagian ke $\mathrm{V}$ adalah kesimpulan.

\section{BAHAN DAN METODE}

\section{A. Persiapan penelitian}

Pada penelitian ini menggunakan simulasi alat (kalibrator) untuk mengecek dan mencoba modul apakah sudah bisa bekrja dengan baik atau tidak, menggunakan rangkaian sensor tekanan dan rangkaian mtotor steppe untuk memodifikasi flow meter manual menjadi flow meter otomatis.

\section{1) Alat dan Bahan}

Penelitian ini menggunakan flow meter manual yang telah dimodifikasi sehingga bisa membuka dan menutup secara otomatis dengan bantuan gear box yang menggunakan motor stepper sebagai penggeraknya. LCD karakter 16 X 4 sebagi tampilan untuk memberitahukan nilai Spo2 pasien dan output oksigen. Dan sensor tekanan untuk mengetahui nilai flow yang sedang dikeluarkan oleh flow meter dengan cara mendeteksi mendeteksi perubahan tekanan ketika adanya perbedaa aliran flow oksigen pada flow meter. Untuk memastikan alat bisa memberikan output aliran oxygen dengan tepat maka peneliti menggunakan alat pembanding yaitu berupa flow meter manual seprti yang berada pada Gambar.1 yang bukaan katup oxygennya di buka pada posisi maksimal, sehingga output oxygen dari modul dapat diketahui dengan melihat bola kecil dari alat pembanding (oxygen flow meter manual).

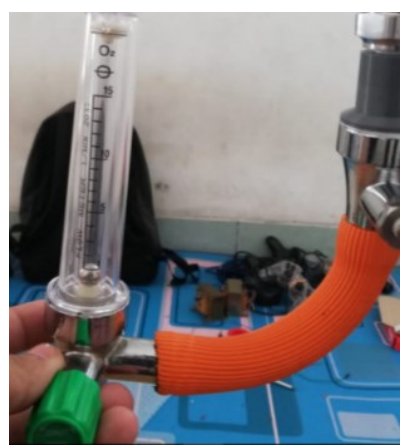

Gambar. 1. flow meter manual sebagi pembanding.

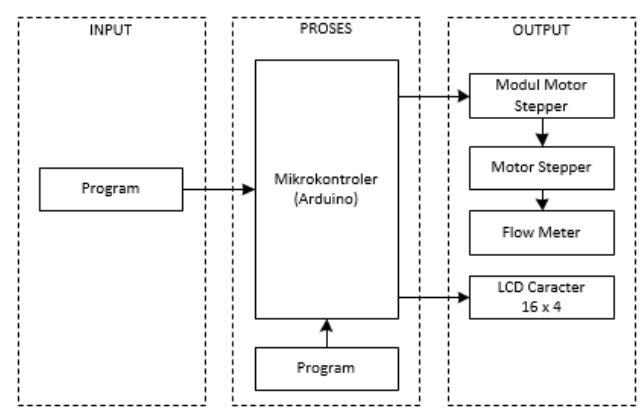

Gambar. 2. Diagram Blok

\section{2) Percobaan}

Dalam penelitian ini peneliti menggunakan sensor tekanan seperti pada Gambar.2, dan mengukur outputnya ketika terjadi perubahan aliran flow pada flow meter, pengukuran ini dilakukan dengan cara membuka katup flow meter dari mulai 
1-15 LPM, dan melihant perubahan tekanannya melalui serial monitor pada Arduino, untuk menambah perbedaan nilai tekanan yang terdapat pada tiap-tiap titik. ,peneliti memodifikasi jalur output oxygen yang berada di dalam flow meter, sehingga aliran oxygen yang terbuka akibat diputarnya katup flow meter akan melewati jalur modifikasi terlebih dahulu, jalur modifikasi akan menjebak aliran oxygen yang mencoba untuk keluar dan menghubungkannya secara langsung dengan sensor tekanan hal ini membuat perbedaan tekanan pada tiap tiap flow bisa di ukur.

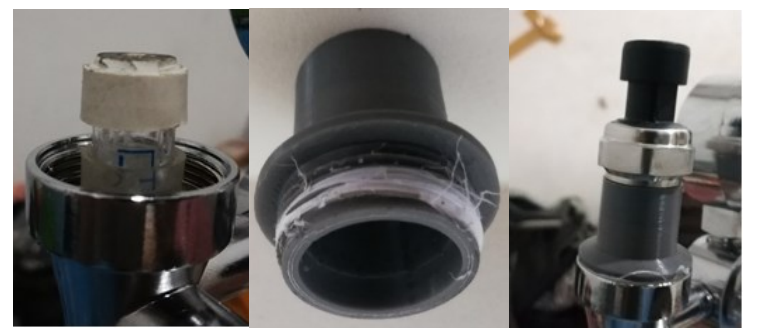

Gambar. 3.

Sensor tekanan yang terpasang pada flow meter dan rangkaian modifikasi yang ada di dalamnya.

setelah di ketahui perubahan nilai tekanan pada tiap titik ouput peneliti bisa menerapkan hasil dari pengukuran output sensor sebagai acuan untuk menggerakka motor stepper,pada Gambar.2 peneliti mengukur rasio yang dimiliki oleh gear motor stepper pada Gambar.3 dan mencoba berbagai gabungan gear sehingga bisa di dapatkan putaran dan torsi yang sesuai untuk memutar katup flow meter untuk bisa di dapatkan output yang diinginkan.

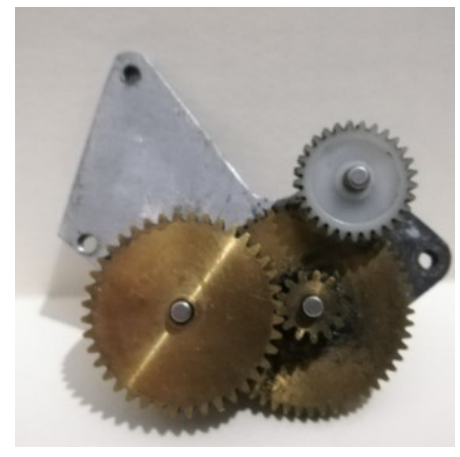

Gambar. 4.

Kombinasi gear yang digunakan

\section{B. Blok diagram}

Pada Gambar.5 bagian yang berada dalam kotak putusputus yang pertama dari sebelah kiri merupakan bagian input, bagian input terdiri dari sensor tekanan, output sensor akan berperan sebagi input data bagi Arduino, bagian yang berada dalam kotak putus-putus yang berada di tengah merupakan bagian proses yang berisi Arduino, Arduino berfungsi sebangi pengolah data sensor sehingga output modul bisa sesuai dengan apa yang di harapkan, pada bagian kotak putus-putus yang berada di sebelah kanan merupakan bagian output yang menerima output pengolahan data dari Arduino sehingga modul dapat bekerja sesuai dengan yang penulis harapkan, bagian output berisi LCD karakter $16 \times 4$ sebagai tampilan, modul motor setepper sebagai penggerak motor stepper,dan motor stepper sebagi penggerak gear yang tersambung pada katup bukaan flow meter.

\section{Diagram Alir}

Diagram alir yang berada pada Gambar.5 merupaka diagram alir sistem dari program Arduinodan dinyalakan akan terdapat plihan mulai, saat kondisi "yes" terpenuhi maka akan masuk ke tampilan konfirmasi untuk memulai, saat kondisi "yes" terpenuhin maka timer ankan dimulai sebagai acuan waktu dan spo2 akan membaca kadar spo2 pasien sebagai acuan pembukaan katup oxygen flow meter saat spo 2 pasien berada pada 88 - 92 maka katup flow meter akan membuka sebesar 2 LPM, setiap 5 menit flow meter akan bertambah sebesar 2 LPM ketika presentase spo2 pasien tetap pada 88 $92 \%$ ketika spo 2 mempunyai presentase di bawah $88 \%$ maka flow meter akan membuka sebesar 6 LPM pada 5 menit awal, ketika tidak terjadi peningkatan spo2 maka bukaan flow meter akan menjadi 10 LPM. Jika presentase spo2 pasien sudah mencapai $92 \%$ maka flow meter akan menutup secara berkala sampai aliran flow berada pada posisi 0 .

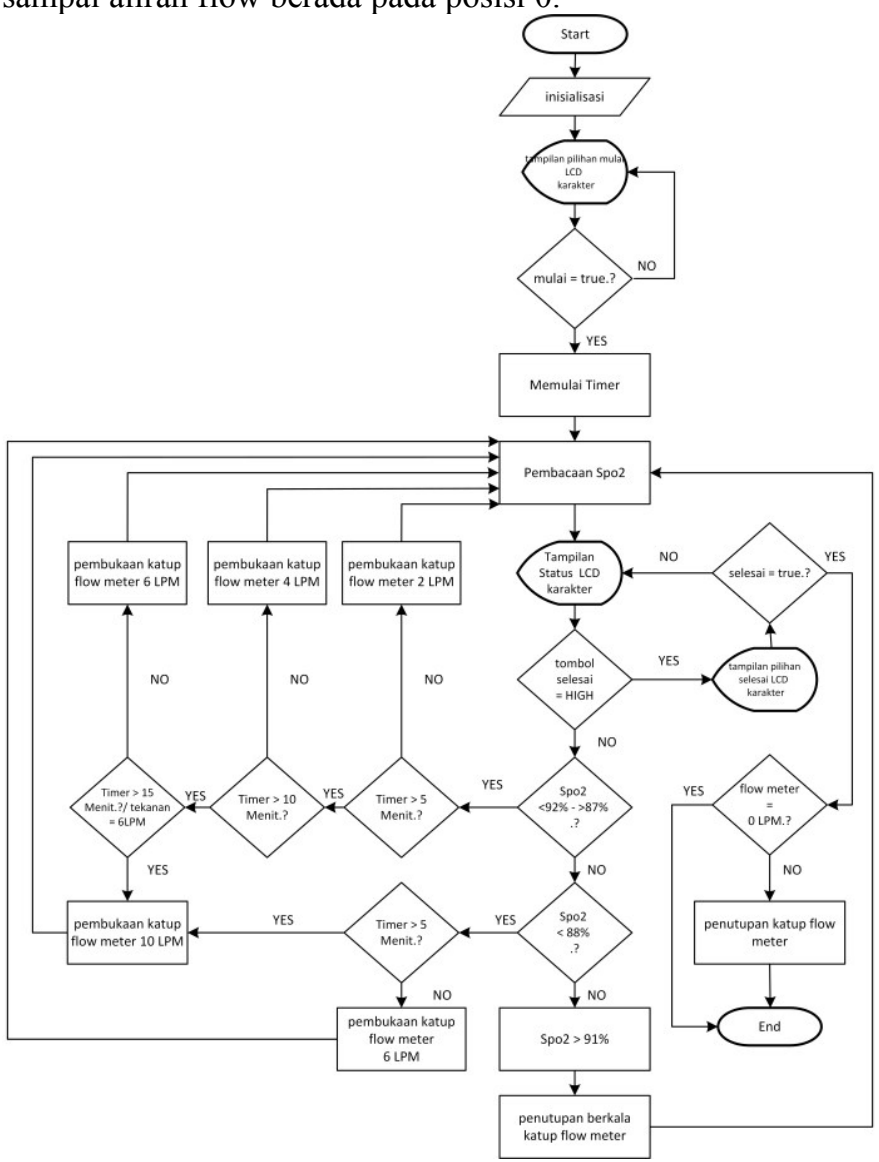

Gambar. 5. Diagram alir dari arduino 


\section{Rangkaian Analog Dan Mekanik}

Bagian terpenting dalam penelitian ini adalah rangkaian anolog sebegai driver motor stepper dan rangkaian mekanik yang mempunyai peran untuk menjadikan flow meter manua menjadi flow meter otomatis.

\section{1) Driver Mototr Stepper}

Rangkaian driver pada motor stepper Gambar.6 menggunakan ic L2986 sebagai penerima logika dan pengolah logika yang diberikan leh pemrograman Arduino

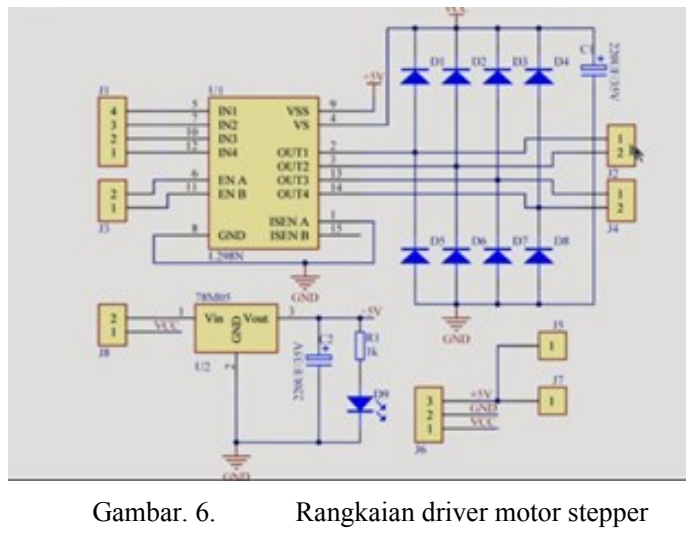

Rangkaian ini berfungsi untuk menerima perintah dari pengolahan data Arduino dan engolahnya menjadi perintah untuk mengontrol putaran motor stepper. sehingga motor stepper dapat berputar sesuai dengan putaran yang diinginkan untuk membuka katup bukaan oxygen pada flow meter yang telah di modifikasi. Pada driver ini terdapat 4 chennel untuk mentriger 4 output tegangan untuk motor stepper. 2 pin untuk mengontrol motor stepper coil A dan 2 pin yang lainya untuk mengontrol motor stepper coil B.

\section{2) Rangkaian Mekanik Untuk Sensor Tekanan}

Rangkaian untuk memodifikasi jalur output pada katup flow meter sangatlah diperlukan dikarenakan sensor tanpa dilakukannya modifikasi sensor tekanan tidak bisa mengetahui perbedaan tekanan pada aliran flow dengan maksimal.

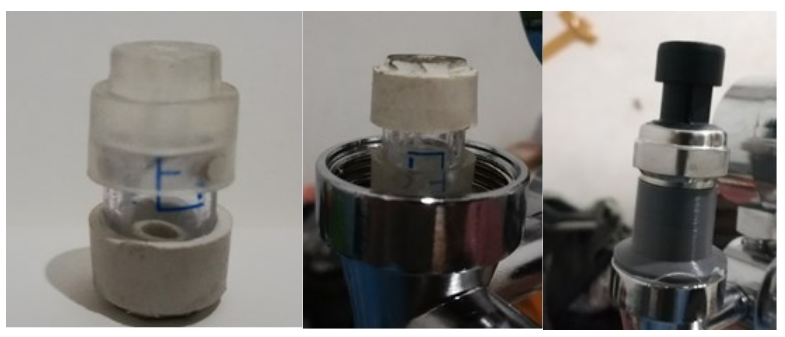

Gambar. 7. Rangkaian penghubung jalur keluar oxygen dengan sensor tekanan

Pada Gambar.7 kami mencoba memodifikasi jalur output dari bukaan katup oxygen flow meter yang berada di dalam, sehingga oxygen yang berada dalam flow meter mempunyai perbedaan tekanan ketika aliran flow berubah dari mulai 1 LPM sampai 15 LPM dengan ketelitian 1 LPM yang dapat digunakan sebagai acuan putaran motor stepper untuk membuka katup bukaan oxygen pada flow meter manual.

\section{3) Microcontroller}

Rangkaian Arduino nano pada Gambar. 8 merupakan rangkaian ardino nano pada umumnya yang telah banyak tersedia di pasaran,

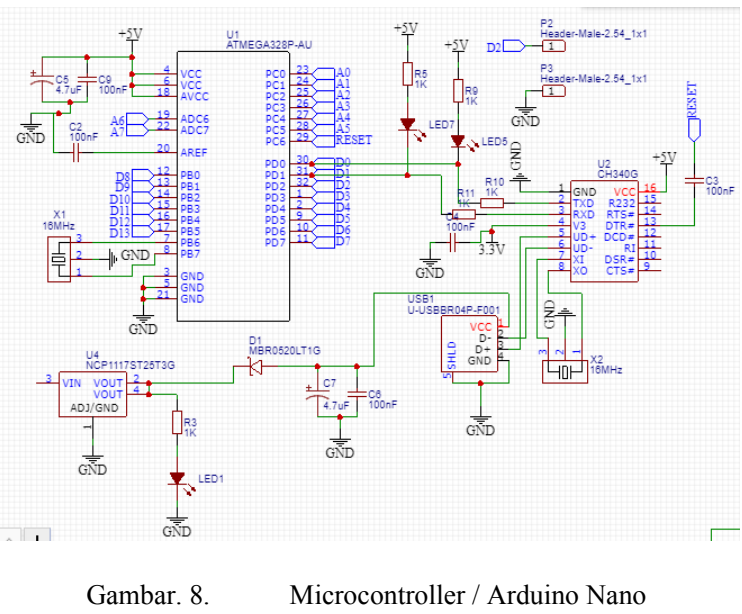

Ardoino merupakan pengolah data yang peneliti gunakan untuk mengolah data output sensor tekanan sebagai acuan untuk mengontrol motor stepper sehingga bisa berputar sesuai dengan kondisi yang diinginkan dalam penelitia ini.

\section{4) Rangkaian Mekanik Untuk Motor Stepper}

Seperti yang terlihat pada Gambar.9 rangkaian gear set / gear box terdiri dari 3 gear yang terhubung satu sama lain, gan ratio gigi yang berbeda beda dengan selain bertujuan untuk menambah torsi dari motor stepper gear box juga berfungsi untuk menambah resulusi tiap putara motor stepper sehingga mendapatkan putaran yang sesuai pada gear yang terakhir untuk membuka katup flow meter dengan akurasi yang maksimal

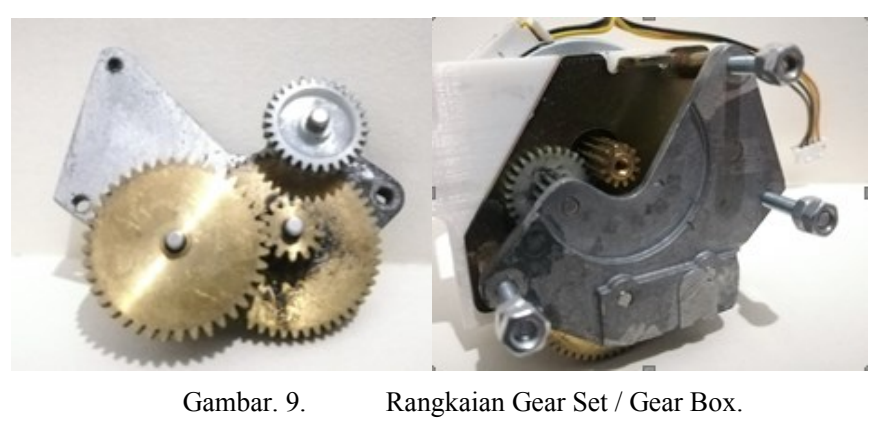

III. HASIL

Pada penelitian ini peneliti belum mensimulasikannya pada pasien yang sesungguhnya, tetapi peneliti mensimulasikan hasil penelitian ini dengan cara mengatur nilai Spo2 secara manual pada nilai dibawah $98 \%-88 \%$, dan mengukur output aliran flow modul menggunakan alat pembanding seperti pada Gambar.1 sehingga peneliti dapat 
mendapatkan data dan hasil yang dibutuhkan untuk penelitian ini, pada Gambar. 10 adalah gambar gabungan rangkaian

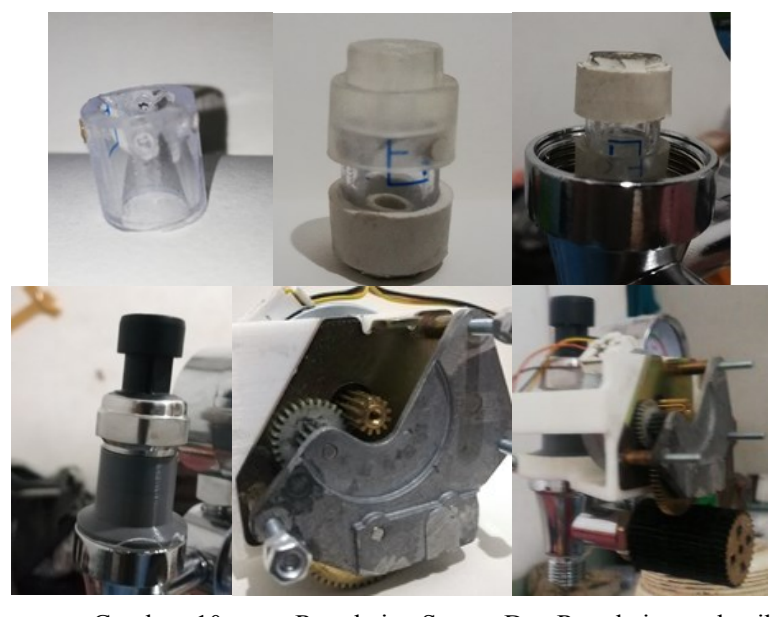

Gambar. 10.

Rangkaian Sensor Dan Rangkaian mekanik

1) Modul Design

Kumpulan foto pada Gambar.10 merupakan kumpulan rangkaian mekanik dan rangkaian sesnsor yang dipakai dalam penelitian ini, rangkaian diatas merupakan hasil dari beberapa percobaab unutk memodifikasi flow meter manual menjadi flow meter digital, rangkaian diatasjuga merupakan hasil modifikasi sehingga sensor tekanan dapat dipakai sebagai acuan data unruk aliran flow yang keluar dari flow meter.

\section{2) Listing Program Pada Arduino}

Listing program Arduino pada penelitian ini mempunyai 3 program utama sebagai pengontrol putaran katup flow meter, program pertama adalah program untuk memulai modul. Bagian kedua merupakan program untuk menampilkan status pada layar LCD karakter $2 \times 16$ dan program yang terakhr merupakan program unutk mengontrol laju dan putaran mototr stepper untuk dapat memutar katup bukaan oxygen flow meter manual dengan acuan nilai presentasi dari Spo 2, bagian ke empat adalah adalah program untuk memberentikan modul.

Listing program 1. Pemilihan untuk memulai modul dengan sistem konfirmasi.

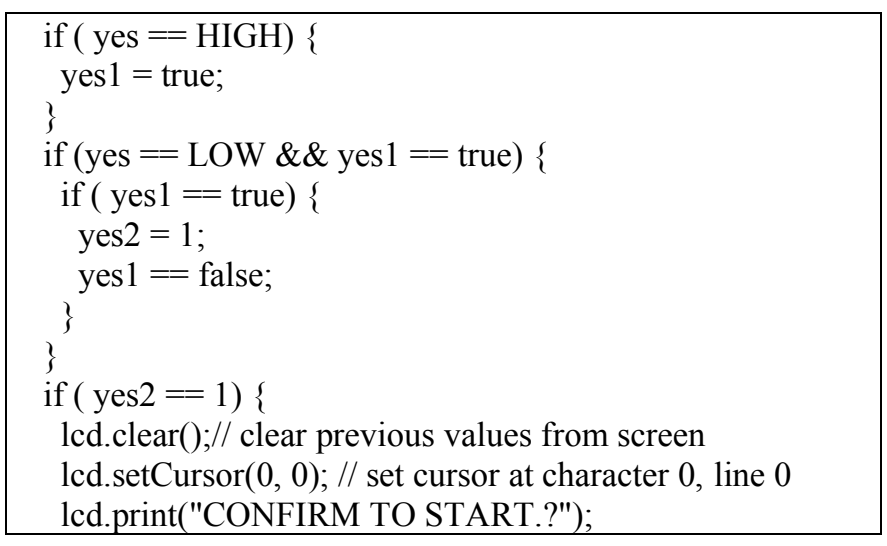

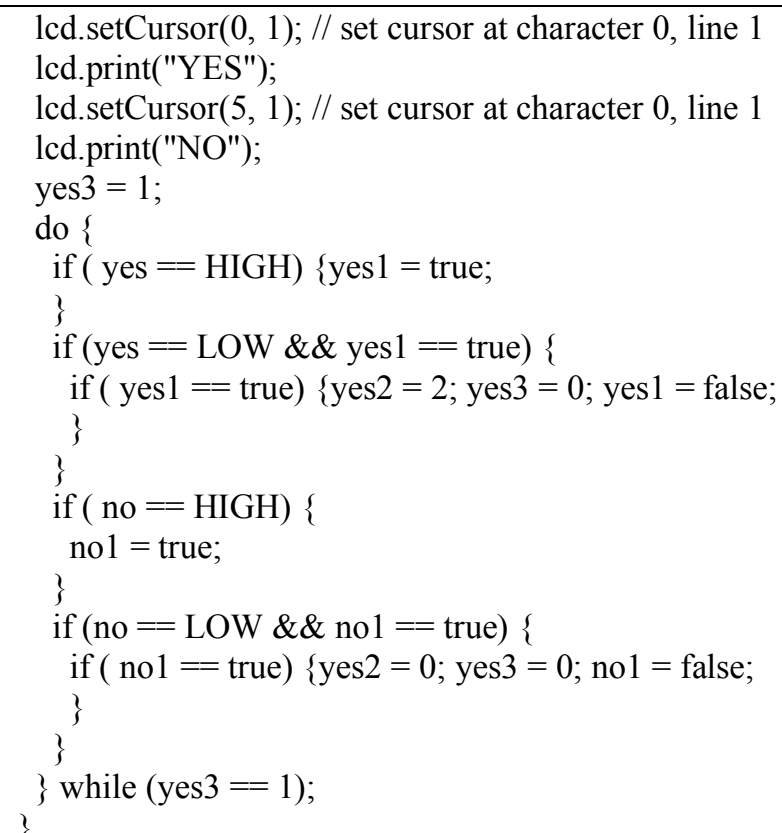

Listing Program 2. Program untuk menujukkan status Spo2 pasien dan satatus aliran flow dan status waktu.

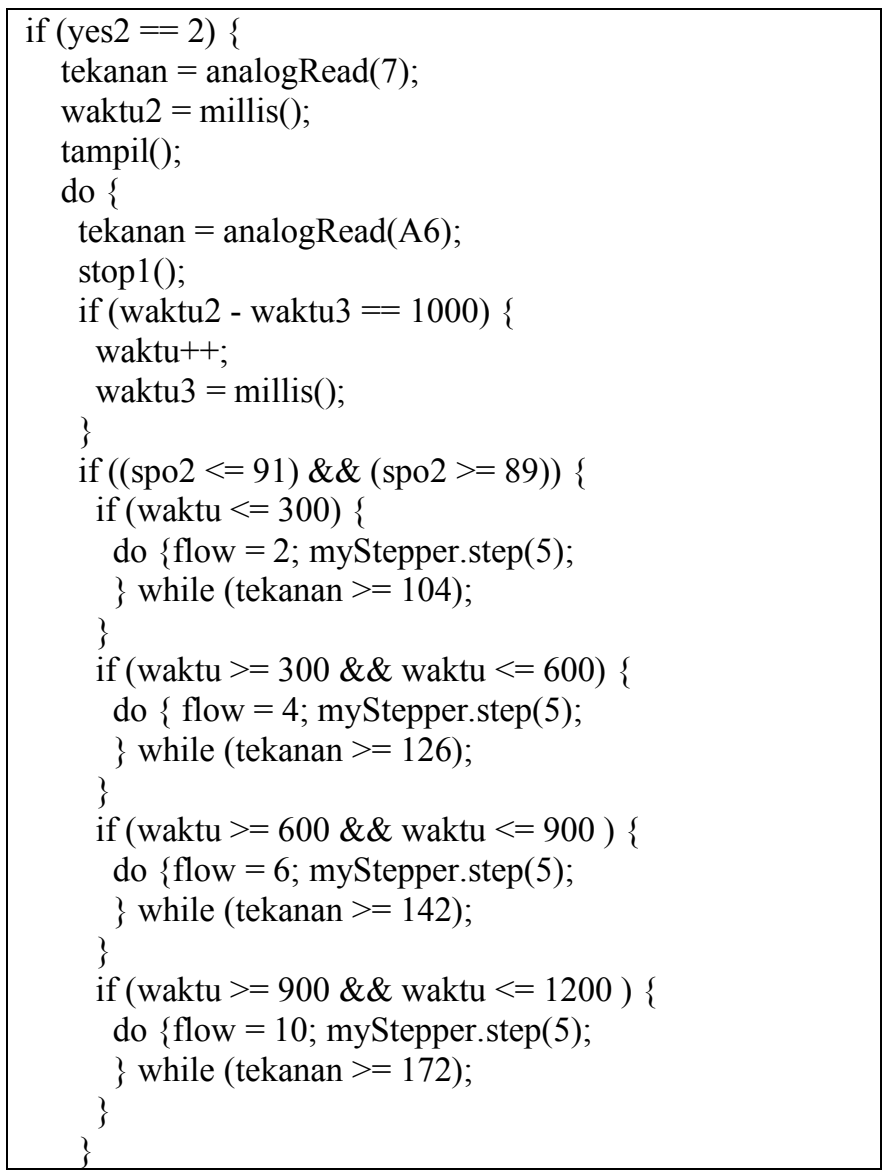




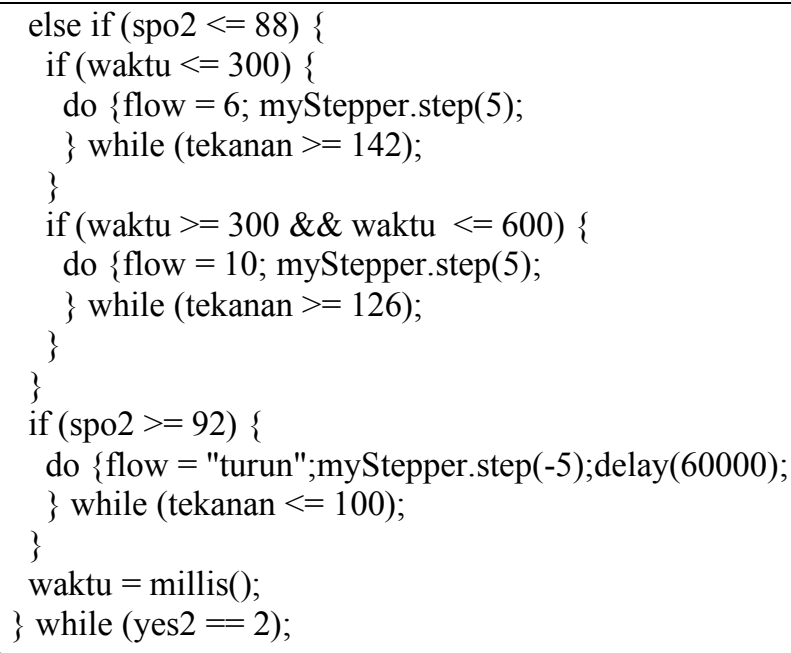

\section{3) Pengukuran Utput Sensor Tekanan Ketika Katup Flow Meter Terbuka}

Berikut merupakan pengukuran output sensor ketika ada aliran flow yang mengalir melalui intput sensor, sehingga sensor dapat mendeteksi perbedaan aliran flow.

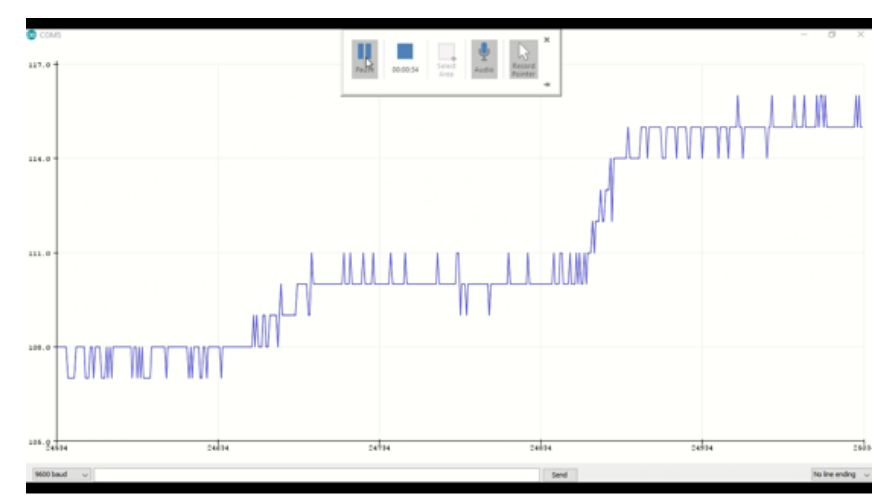

Gambar. 11. Output Sensor Tekanan Ketika Ada Flow

Gambar. 11Adalah hasil percobaan untuk mengukur perbedaan tekanan yang dimiliki oleh aliran flow pada titik 2 4 LPM, dengan cara melihat data ADC output sensor pada Arduino, pada garis biru yang paling bawah, posisi flow berada pada 2 LPM, pada garis biru yang tengah, posisi flow berada pada 3 LPM, pada garis biru yang paling atas,posisi flow berada pada 4 LPM.

\section{4) Error Pada Output Sensor Untuk Membaca Perbedaan} Tekanan Aliran Flow

Untuk menguji kestabilan dan ketepatan modul, peneliti melakukan simulasi sebanyak 5 kali yang dapat dilihat pada TABEL I.
TABLE I. ERROR PADA OUTPUT SENSOR UNTUK MEMBACA PERBEDAAN ALIRAN FLOW

\begin{tabular}{|c|c|}
\hline Percobaan & Error (\%) \\
\hline 1 & 0.1 \\
\hline 2 & 0.2 \\
\hline 3 & 0.1 \\
\hline 4 & 0.3 \\
\hline 5 & 0.1 \\
\hline $\begin{array}{c}\text { Average } \\
\text { Error }\end{array}$ & 0.16 \\
\hline
\end{tabular}

Dari percobaan simulasi diatas didapatkan ketidak setabilan output sensor tekanan pada saat membaca aliran flow yang tetap, hasil pengukuran simulasi bisa dilihat pada Gambar.11.

\section{5) Error Pada Output Flow Yang Diinginkan Dengan Output} Flow Yang Sebenarnya

Hasil dari pensimulasian Spo2 untuk mengetahui ketepatan output Flow Meter dengan kondisi outpu yang diinginkan dapat dilihat dari TABEL II.

TABLE II. ERROR PADA OUTPUT FLOW YANG DIINGINKAN DENGAN OUTPUT FLOW YANG SEBENARNYA MENGGUNAKAN SIMULASI DENGAN PEMBANDING (FLOW METER UMUM)

\begin{tabular}{|c|c|}
\hline Percobaan & Error (\%) \\
\hline 1 & 0.3 \\
\hline 2 & 0.4 \\
\hline 3 & 0.1 \\
\hline 4 & 0.3 \\
\hline 5 & 0.5 \\
\hline $\begin{array}{c}\text { Average } \\
\text { Error }\end{array}$ & $1.2 \%$ \\
\hline
\end{tabular}

Berdasarkan hasil percobaan simulasi yang lalu dibandingan dengan flow meter umum untuk mengetahui output flow meter yang sesungguhnya di dapatkan error ratarata sebesar $1.2 \%$.

\section{DISKUSI}

Berdasarkan beberapa percobaan yang dilakukan untuk membuat sensor tekanan bisa untuk membaca perbedaan tekanan atau (force) dari aliran flow,cara yang tebaik untuk bisa membuat sensor tekanan dengan jelas memberikan pebedaan output maka adalah dengan membuat jalur keluaran oxygen pada katup flow meter umum seperti pada Gambar.6. pada Gambar.8 menujukkan bahwa kombinasi dari beberapa gear diperlukan untuk membuat torsi dan resolusi tiap putara motor stepper sesuai dengan yang diinginkan. Dan pada Gambar.9 dapat di perhatikan rangkaian keseluruhan yang dibuat oleh peneliti untuk memodifikasi flow meter manual 
menjadi otomatis. Pada pemodifikasian ini akan membuat akurasi dan presesi dari penggunaan flow meter bertambah karena menggunakan sensor sebagai pendeteksi aliran flow [20], yang pada penelitain sebelumnya belum menggunakan sensor digital untuk mengetahui berapa aliran flow yang sedang digunakan [12]. Dan secara otomatis memutar bukaan katup flow meter.meskipun terdapat peningkatan terhadap akurasi terdapat beberapa hal yang harus di pertimbangkan. Yaitu ketahanan sensor, umur dari sensor, dan juga ketahanan dari motor stepper.

\section{KESIMPULAN}

Tujuan utama dari penelitian ini adalah untuk mempermudah tugas perawat dan menjaga pasien yang membutuhkan oksigen terapi agar mendapatkan tambahan oksigen sesuai dosis yang di perlukan. Dalam proses penelitian ini di dapatkan kesimpulan bahwa flow meter manual bisa di modifikasi utuk dijadikan otomatis dengan cara menambahkan beberapa part dan sensor tekanan untuk mengetahu perbedaan tekanan dari aliran flow 1 - 15 LPM. Dalam penelitian ini juga di temukan bahwa sensor tekanan daapat dipakai untuk mengetahui perbedaan tekanan pada aliran flow tertentu. Secara ringkas penelitia ini berhasil untuk memodifikasi flowmeter manual menjadi otomatis dengan cara mengganti dan menambahkan beberapa part yang di butuhkan. Untuk penelitian selanjutnya peneliti menyarankan agar bisa membuat flow meter central, agar bisa untuk mengatur beberapa flow meter dalam satu device.

\section{DAFTAR PUSTAKA}

[1] R. A. C. Siemieniuk et al., "Oxygen therapy for acutely ill medical patients: a clinical practice guideline," no. October, 2018, doi: 10.1136/bmj.k4169.

[2] M. Tulong and M. Hatibie, "Pola penggunaan terapi hiperbarik di RSUP Prof. Dr . R . D . Kandou," vol. 4, pp. 4-8, 2016.

[3] R. Choudhury, "Hypoxia and hyperbaric oxygen therapy : a review," pp. 431-442, 2018.

[4] M. Hardinge et al., "British Thoracic Society guidelines for home oxygen use in adults," 2015, doi: 10.1136/thoraxjnl-2015-206865.

[5] B. T. S. Guideline, F. O. R. Oxygen, I. N. Adults, I. N. Healthcare, and E. Settings, "Bts guideline for oxygen use in adults in healthcare and emergency settings," vol. 72, no. June, 2017.

[6] B. R. O. Driscoll, L. S. Howard, A. G. Davison, and T. Society, "BTS guideline for emergency oxygen use in adult patients," vol. 63, no. Gambar 2, 2008, doi: 10.1136/thx.2008.102947.

[7] R. Balkissoon, "Journal of the COPD Foundation Chronic Obstructive Pulmonary Diseases: Journal
Club : COPD and Oxygen Therapy," vol. 4, no. 1, pp. 71-75, 2017.

[8] B. T. Society, "BTS Guidelines for Home Oxygen Use in Adults," vol. 70, no. June, 2015.

[9] O. Procedure, "AARC Clinical Practice Guideline Oxygen Therapy in the Home or Alternate Site Health Care Facility - 2007 Revision \& Update," pp. 10631068, 2007.

[10] B. E. S. Mb, "The USCOM and Haemodynamics A Guide for Junior Medical and Nursing Staff."

[11] S. T. Group, "Hypoxemia in the ICU : prevalence , treatment , and outcome," 2018, doi: 10.1186/s13613018-0424-4.

[12] S. Behbahani and M. A. Pishbin, "New Oxygenation Method Based on Pulse Oximeter," vol. 2, no. 4, pp. 185-188, 2012, doi: 10.5923/j.ajbe.20120204.06.

[13] S. K. Jindal, "Oxygen Therapy: Important Considerations," 2008 .

[14] B. S. Rasmussen, A. Perner, J. Wetterslev, C. S. Meyhoff, and O. L. Schjørring, "oxygenation," p. 2437, doi: 10.1016/S0140-6736(18)32194-9.

[15] B. M. Cataletto, "Fundamentals of oxygen therapy," Dep. Pediatr., no. April, pp. 22-24, 2011.

[16] I. Series, "Oxygen Therapy," vol. 171, no. April, 2016.

[17] P. C. Llew and A. Ganendran, "OXYGEN FAILURE : A POTENTIAL DANGER WITH AIRFLOWMETERS IN ANAESTHETIC MACHINE WITH REMOTE CONTROLLED,” pp. 1165-1168, 1973, doi: 10.1093/bja/45.11.1165.

[18] B. Medi-, A. Nocturnal, O. Therapy, C. C. Survey, T. Cardiac, and A. Suppression, "Evidence-based oxygen therapy: Missed and future opportunities Oxigenoterapia baseada na evidência: Oportunidades perdidas e futuras," vol. 18, no. 6, pp. 257-259, 2012.

[19] D. G.R., McCutcheon, J.A., Clinical Procedures for Safer Patient Care, 4.0. .

[20] D. W. Wheeler, "Air and oxygen flowmeter confusion Air and oxygen flowmeter," no. May, 2015, doi: 10.1258/jrsm.2008.080198. 